\title{
INFLUÊNCIAS DAS RELAÇÕES INTRAFAMILIARES NO COMPORTAMENTO DE CRIANÇAS QUE FREQUENTAM CRECHES PÚBLICAS DE ALFENAS
}

\author{
Michelly Rodrigues ESTEVES ${ }^{a}$, Geisiane Karla CARRIJO ${ }^{b}$, Maria Betânia Tinti de ANDRADE, \\ Lana Ermelinda da Silva dos SANTOS ${ }^{d}$, Maria das Graças Carvalho FERRIANI ${ }^{\mathrm{e}}$
}

\section{RESUMO}

Nos últimos anos, as organizações sociais e familiares se modificaram, tornando as creches mais requisitadas pela população. Nosso objetivo foi compreender as influências das relações intrafamiliares no comportamento das crianças de 0 a 3 anos, que frequentam creches, por meio das experiências vivenciadas por seus monitores. Pesquisa qualitativa, utilizando a Trajetória Fenomenológica, com entrevista de 12 monitores de seis creches públicas municipais. Como categorias: reprodução de comportamentos apreendidos no ambiente familiar; integração família-creche como facilitadora do trabalho desempenhado pelos monitores; déficit de cuidados higiênicos oferecidos pela família. Estudos futuros poderão promover melhorias nas ações dos cuidadores frente às necessidades infantis, apontando para uma melhor qualidade de vida das crianças, contribuindo para o desenvolvimento de todo o seu potencial.

Descritores: Criança. Família. Creches.

\section{RESUMEN}

En los últimos años, las organizaciones sociales y familiares se modificaron, volviendo los centros de educación infantil más solicitados por la población. Nuestro objetivo era comprender las influencias de las relaciones intrafamiliares en el comportamiento de niños de O-3 años que asisten a centros infantiles a través de las experiencias de sus monitores. Investigación cualitativa, uso Trayectoria Fenomenológica, entrevistados 12 monitores de seis centros públicos municipales. Como categorías: Reproducción de comportamientos aprendidos en el ambiente familiar; Integración familia-centro educacional infantil como facilitador del trabajo desempeñado por las monitoras; Déficit de cuidados higiénicos ofrecidos por la familia. Estudios futuros podrían promover mejoras en las acciones de los cuidadores frente a las necesidades infantiles, dando un direccionamiento para una mejor calidad de vida de los niños, contribuyendo para el desarrollo de todo su potencial.

Descriptores: Niño. Familia. Jardines infantiles.

Título: Influencias de las relaciones intrafamiliares en el comportamiento de niños en centros infantiles de Alfenas.

\section{ABSTRACT}

In recent years, social organizations and families have changed, leading to an increase in the nursery school demand by the population. Our aim was to understand the influences of intra-family relationships on the behavior of children ages O-3 years old who attend nursery schools through the experiences of their child care providers. A qualitative research, using Phenomenological Approach, in which 12 child care providers of six municipal nursery schools were interviewed. As categories: Reproduction of behaviors learned in the family atmosphere; Integration family-nursery school as a facilitator of the work carried out by the child care providers; Lack of hygienic care offered by the family. Future studies could promote improvements in the actions of caregivers towards the children's needs, leading to a better quality of life for the children and helping to develop their full potential.

Descriptors: Child. Family. Nursery schools.

Title: Influences of intra-family relationships on the behavior of children attending public nursery schools in Alfenas.

\footnotetext{
a Doutoranda pelo Departamento Materno-Infantil Saúde Pública (DMISP) da Escola de Enfermagem de Ribeirão Preto da Universidade de São Paulo (EERP-USP), Ribeirão Preto, São Paulo, Brasil.

b Especialista em Residência Enfermagem em Terapia Intensiva do Hospital e Maternidade Celso Pierro da Pontifícia Universidade Católica de Campinas (HMCP-PUC Campinas), Campinas, São Paulo, Brasil.

c Mestre em Enfermagem, Professora Adjunta e Diretora da Escola de Enfermagem da Universidade Federal de Alfenas (UNIFAL-MG), Alfenas, Minas Gerais, Brasil.

d Pós-Doutora em Enfermagem, Professora Associada e Pró-reitora de graduação da UNIFAL-MG, Alfenas, Minas Gerais, Brasil.

e Professora Titular e Chefe do DMISP da EERP-USP, Ribeirão Preto, São Paulo, Brasil.
} 


\section{INTRODUÇÃO}

A primeira creche citada na literatura foi fundada na França, na região dos Vosges, em 1770, destinada a assistir lactentes de famílias de camponeses. No Brasil, as primeiras instituições criadas tinham como objetivo esconder e cuidar dos filhos das mães solteiras abandonados nas portas e nas igrejas, diante das casas particulares ou na "roda dos expostos” das Santas Casas de Misericórdia ${ }^{(1)}$.

Devido à expansão do processo de industrialização e de urbanização, bem como a maior participação da mulher no mercado de trabalho, as creches, também denominadas Centros de Educação Infantil (CEI), têm sido mais requisitadas, constituindo o local onde a criança permanece por até 12 horas em todos os dias úteis, realizando neste período cinco refeições ${ }^{(2)}$.

A Constituição Brasileira ${ }^{(3)}$, ao incluir a educação infantil no sistema educativo, passou a legitimá-la como direito da criança, dever do Estado e opção da família. Em tempo posterior, o Estatuto da Criança e do Adolescente (ECA) ${ }^{(4)}$ reforçou os dispositivos constitucionais sobre a educação de 0 a 6 anos, impulsionando principalmente o crescimento de creches mantidas pelo poder público. Com a Lei de Diretrizes e Bases da Educação Nacional (LDB) ${ }^{(5)}$, a educação infantil foi colocada como a primeira etapa da educação básica. Define a lei que o atendimento de 0 a 3 anos será feito em creches e de 4 a 6 anos, em pré-escolas. A creche, assim como a pré-escola, é equipamento educacional e não apenas de assistência. Neste sentido, uma das características da nova concepção de educação infantil reside na integração das funções de cuidar e educar.

A LDB explicita também que cabe a cada Conselho Municipal de Educação definir regulamentações para o funcionamento das instituições de educação infantil (com base em referenciais nacionais), ficando a cargo das Secretarias Municipais de Educação tanto a autorização como a supervisão das instituições ${ }^{(5)}$.

As creches devem ser ambientes ricos em recursos de estimulação ao desenvolvimento infantil por ser uma fase na qual a criança começa a adquirir conhecimentos e capacidades importantes para o bom desempenho não apenas escolar, mas também social e emocional. O meio assume um papel relevante uma vez que em um ambiente estimulante e facilitador a criança se desenvolverá de forma natural respeitando o ritmo individual ${ }^{(6)}$.
Essas instituições devem oferecer processos educativos que propiciem alimentação equilibrada e segura do ponto de vista sanitário, além de promoverem educação alimentar, nutricional e de higiene às crianças e as suas famílias( ${ }^{(7)}$.

Diante do exposto, a Enfermagem deve contribuir para a atenção à criança na creche, orientando os familiares e os educadores; realizando intervenções pontuais de controle de saúde e ajudando a construir um referencial que possibilite o cuidado infantil integral que implica na interação constante entre adultos e crianças, incluindo atividades que integram educação, acolhimento, alimentação, limpeza, conforto e proteção.

O presente estudo resulta de um trabalho de conclusão de curso para obtenção do título de bacharel em Enfermagem ${ }^{(8)}$ e se justifica pelo interesse em novas reflexões referentes ao comportamento de crianças que frequentam creches com o propósito de melhorias nas ações dos cuidadores frente às necessidades infantis, contribuindo para a ampliação de estudos na área. Tem por objetivo compreender as influências das relações intrafamiliares no comportamento das crianças de 0 a 3 anos que frequentam creches por meio das experiências vivenciadas por seus monitores.

\section{TRAJETÓRIA METODOLÓGICA}

Correspondeu a uma pesquisa com a abordagem metodológica qualitativa, utilizando a Trajetória Fenomenológica ${ }^{(9)}$ que tem como propósito investigar de forma direta as vivências humanas e compreendê-las, sem se prender a explicações causais ou a generalizações.

Fenômeno é algo que pode tornar-se manifesto, que se mostra a si mesmo. A Trajetória Fenomenológica é constituída de três momentos: a descrição, a redução e a compreensão(10).

No momento da descrição, tivemos acesso às situações vividas pelo sujeito. Na redução, evidenciamos as partes essenciais da descrição. Já na compreensão, alcançamos os significados atribuídos pelos sujeitos.

Por meio da compreensão, chegamos à construção final dos resultados, com o objetivo de nos apropriarmos do objeto de estudo em sua intenção total.

A repetição das falas indicou a saturação dos dados, a manifestação do fenômeno, os significados essenciais foram apreendidos de forma esclarecedora. 
Os sujeitos da pesquisa foram monitores de seis creches públicas do município de Alfenas, localizado no Sul de Minas Gerais, onde são assistidas aproximadamente 1.052 crianças, sendo esta a região de inquérito. Para a realização deste estudo não houve referência institucional, sendo mantida a privacidade dos monitores. Os princípios éticos da pesquisa com seres humanos atenderam as especificações da Resolução 196/96 $6^{(11)}$.

Após a apreciação e a aprovação pelo Comitê de Ética em Pesquisa da Universidade Federal de Alfenas (UNIFAL-MG), protocolo $\mathrm{n}^{\circ}$ 23087.004884/2008-20, foram realizadas um total de 12 entrevistas, mediante a autorização da Secretaria Municipal de Educação e dos diretores das instituições.

Posteriormente à assinatura do Termo de Consentimento Livre e Esclarecido, os sujeitos foram abordados com a questão norteadora: Quais as influências das relações intrafamiliares no comportamento das crianças de o a 3 anos que frequentam a creche?

\section{APRESENTAÇÃO E DISCUSSÃO DOS RESULTADOS}

Após leituras exaustivas de cada uma das transcrições com o propósito de apreendermos as experiências e os sentidos trazidos pelos entrevistados, selecionamos as unidades de significado, as quais originaram as seguintes categorias:

\section{Reprodução de comportamentos apreendidos no ambiente familiar}

A família pode ser referida como o principal grupo social na formação do indivíduo, apresentando como papel fundamental o atendimento às necessidades biopsíquica, socioespiritual e cultural de cada um de seus componentes. Desempenha o papel estabelecido socialmente de ensinar, de proteger e de satisfazer as necessidades básicas da criança durante a sua vida. A formação do vínculo da criança com a família acontece desde a gestação e é fundamental para que a mesma consiga desenvolver-se de maneira saudável ${ }^{(12)}$.

O final do primeiro ano de vida, que necessita de cuidado vigilante, caracteriza-se como um momento importante do desenvolvimento infantil, uma vez que a criança apresenta novas aquisições em termos de linguagem, de locomoção e de exploração do ambiente. Ocorrem mudanças expressivas em seu desenvolvimento que vão desde o crescimento físico até o emocional, há uma maior capacidade para realizar movimentos de afastamento e de reaproximação. Aos 12 meses de idade, o bebê aprende a andar, imita comportamentos dos adultos, gosta de tomar decisões e iniciativas e, geralmente, quer ter o controle de suas separações em relação aos pais, não tolerando que estes se afastem dele. As novas aquisições de habilidades motoras acabam repercutindo nas rotinas do cotidiano do bebê, como em atividades do sono e de alimentação, entre outras. Além disso, estas capacidades possibilitam à criança adquirir novas perspectivas sobre os objetos e as situações, além de utilizá-las como parte de seu comportamento exploratório $^{(13)}$.

Por meio dos relatos dos sujeitos, compreendemos que uma criança com pais afetivos e um lar bem-estruturado, no qual existe conforto e proteção, pode desenvolver sentimentos de segurança e de confiança em si mesma e em relação àqueles que convivem com ela. De outra forma, se uma criança cresce afastada da vida familiar, inferimos que sua base de segurança tende a reduzir, o que pode prejudicar suas relações com os outros e acarretar possíveis prejuízos nas demais funções de seu desenvolvimento.

A criança que convive e tem mais apoio da família, ela é mais concentrada e aquela família que é mais desestruturada, a criança também tem mais agito [...] (2).

A casa é muito importante e influencia a vida da criança $[\cdots]\left(6_{1}\right)$.

Crianças de o a 3 anos encontram-se em uma fase de intensa exploração do ambiente e podem aprender modelos cognitivos e comportamentais a partir de eventos diários, incluindo-se a observação de seus pais em situações interparentais. Portanto, pais que praticam atos violentos e utilizam a punição estão mostrando a seus filhos que a violência é uma forma apropriada de resolução de conflitos e de relacionamento. Com o intuito de disciplinar os filhos, as punições físicas e psicológicas têm feito parte da educação dada pelos pais. Os castigos físicos severos, ocorridos no meio familiar, constituem violência doméstica e podem gerar comportamentos antissociais nas crianças $^{(14)}$.

A ideia de que o meio familiar pode ser transportado para a creche é o que prevalece nos tem- 
pos atuais. $\mathrm{O}$ momento em que a criança vai para a creche está marcado pelo instante de separação da família e neste sentido, a creche representa um espaço privilegiado para oferecer à criança oportunidades e alternativas que estimulem suas potencialidades. Contudo, ressaltamos que mesmo que a creche atenda às necessidades da família em termos da disponibilidade de seu tempo, é imprescindível que se esteja atento para o que a criança está sentindo e como são utilizadas e preenchidas estas longas horas de afastamento familiar e permanência na creche.

Os sujeitos demonstraram sensibilidade ao se referirem à realidade vivenciada pela criança dentro do ambiente familiar. Reconheceram a relevância de buscarem compreensão acerca do contexto em que cada criança encontra-se inserida visando ao cuidado infantil mais efetivo.

[...] a gente tem que saber entender a família, às vezes, é muito desestruturada e a criança passa por aquilo, sem querer "tadinhos" porque eles não têm culpa de nada, mas mesmo assim acaba afetando eles $\left(1 \mathrm{O}_{3}\right)$.

Embora a estrutura familiar esteja enfrentando mudanças e a creche surja como alternativa de auxílio às famílias, permanece a convicção de que a responsabilidade primordial quanto ao cuidado e à educação infantil está na família visto que a mesma concentra possibilidades de constituição das pessoas como sujeitos e cidadãos.

\section{Integração família-creche como facilitadora do trabalho desempenhado pelas monitoras}

A família e o sistema educacional emergem como duas instituições fundamentais para desencadear os processos evolutivos das pessoas, atuando como propulsoras ou inibidoras do seu crescimento e do seu desenvolvimento físico, intelectual, emocional e social ${ }^{(12)}$.

Nos três primeiros anos de vida da criança, a família tem função essencial no processo de socialização, cuidados psicológico e afetivo. Contudo, a família não é o único contexto em que a criança tem a oportunidade de experienciar e de ampliar a sua aprendizagem, a creche também tem sua parcela de contribuição no desenvolvimento infantil. Conforme relatos, os sujeitos fizeram menção à importância da participação da família junto à creche como facilitadora de um trabalho qualificado.
[...] a família tem que ser mais amiga das monitoras, professoras para poder ajudar porque só a creche não consegue $[\ldots]\left(12_{2}\right)$.

Em tempos passados, a educação dos filhos era destinada à mãe, que também cuidava da administração da rotina doméstica e do comando dos serviçais. As crianças não se separavam dos adultos, conseguindo com isso observar e compartilhar experiências diversas ${ }^{(15)}$.

No contexto atual, em diversas situações, a mulher tem dificuldades em conciliar o trabalho doméstico com os cuidados dos filhos. A criança se torna responsabilidade de toda a família numa rede de sociabilidade na qual todos participam. Novamente, a creche surge como apoio para esta família, auxiliando no cuidado da criança.

[...] muito boa essa influência que a gente tem diretamente com a família porque a gente acaba entendendo o comportamento das crianças $[\ldots]\left(10_{2}\right)$.

A interação entre pais, creches e crianças constitui algo primordial já que se estabelecem vínculos afetivos significativos e essenciais ao bem estar infantil. Isto quer dizer que ocorre um enriquecimento da qualidade das experiências infantis, permitindo-lhes ter confiança em si próprias, sentirem-se aceitas, ouvidas, cuidadas e amadas, de forma a lhes oferecer segurança para a sua formação pessoal e social, para o desenvolvimento de sua identidade e conquista da autonomia $^{(16)}$.

Os monitores referiram que os pais são atentos quanto às solicitações das creches e que dentro de suas possibilidades, são participativos. Esta seria a condição primordial para a satisfação destes profissionais com o trabalho realizado junto às crianças o qual é capaz de proporcionar um bom crescimento e desenvolvimento das mesmas.

[…] os pais são participativos, tudo o que você pede, de uma forma ou de outra, estão participando [...] (62).

Para que a família confie na creche, é fundamental o acesso ao espaço interno da instituição para que os familiares observem de perto onde o filho vai permanecer durante o dia, conhecendo os colegas de classe, conversando com o educador responsável e observando o local onde as refeições são preparadas e servidas ${ }^{(7)}$. 
Percebemos que o diálogo estabelecido entre os monitores e os familiares propicia a integração entre ambos. A família reconhece a creche como um alicerce gerador de bem-estar infantil, em contrapartida, a creche adquire condições de adentrar o cotidiano de cada criança, podendo conhecer as causas de seus comportamentos.

\section{Déficit de cuidados higiênicos oferecidos pela família}

Entre as necessidades primordiais do ser humano, encontra-se a necessidade de higiene. No que se refere à criança, os cuidados higiênicos são importantes porque as protegem de doenças e geram bem-estar. As condições higiênico-sanitárias da moradia e do ambiente aos quais as crianças estão submetidas podem contribuir de forma significativa para uma maior prevalência de problemas de saúde ${ }^{(17)}$.

Dentre as afecções que acometem principalmente as crianças, as enteroparasitoses estão relacionadas com níveis socioeconômicos mais baixos e condições precárias de saneamento básico. A maioria desses parasitas pode comprometer as crianças física e intelectualmente ${ }^{(18)}$.

Os sujeitos referiram que os cuidados higiênicos oferecidos pelas famílias às crianças são deficitários.

[...] a questão da higiene [...] a criança não vem com uma higiene boa de casa (2).

Uma característica do desenvolvimento humano é a grande dependência da criança pelos adultos que a cercam. A família é quem irá dispor de condições necessárias para promover soluções frente às situações adversas. Para um crescimento e desenvolvimento saudável, a criança necessita dos mais variados estímulos, como o olhar, o acariciar, o abraço, o brincar, o aconchego, a atenção, os atos de alimentar e de orientar nas questões de higiene. É importante aproveitar todas as oportunidades para esta estimulação ${ }^{(16)}$.

Nos discursos, os sujeitos demonstraram preocupação no que diz respeito às condições higiênicas das crianças. Mencionaram que muitas delas, ao retornarem de seus lares para a creche apresentam indícios de ausência de banho observados pelo desmazelo com as roupas e pelas hiperemias.

[...] quando vão pra casa, no final de semana, em algumas crianças acontecem casos de hiperemia $\left(1_{2}\right)$.
Tem crianças que em casa são tão maltratadas que você vêpela roupa, nem banho toma, a mãe não liga pro filho, tem aquelas crianças que apresentam sujeira $[\ldots]\left(8_{1}\right)$.

É importante reconhecer que o banho todos os dias e a troca de fralda toda vez que a criança estiver molhada, protegem a pele das hiperemias, que podem infeccionar e causar outras doenças. Manter limpos o ambiente, os utensílios e as superfícies para a preparação e para a administração dos alimentos, utilizando água fervida ou filtrada também constituem medidas de higiene ${ }^{(19)}$.

Os pais ou algum membro da família devem ser incentivados a participar do cuidado prestado aos filhos. Ressaltamos, portanto, a responsabilidade do profissional de Enfermagem quanto à orientação de cuidados higiênicos aos familiares.

Cuidar das crianças e de suas famílias constitui uma responsabilidade e um compromisso moral do Enfermeiro e para tanto é necessário que haja um ambiente de cuidado que favoreça a construção de uma prática que ajude no atendendo às necessidades humanas básicas A Enfermagem necessita acompanhar as questões globais que determinam mudanças na dinâmica familiar para melhor compreender e intervir no sentido de favorecer a saúde de seus membros. É preciso aprofundar o conhecimento da realidade da família contemporânea para subsidiar ações de Enfermagem que auxiliem no enfrentamento das dificuldades enfrentadas pelas famílias que têm seus filhos frequentando as creches ${ }^{(20)}$.

\section{CONSIDERAÇÕES FINAIS}

A família constitui o primeiro núcleo de socialização do indivíduo e contribui de forma essencial para a sua formação.

Deste modo, as crianças reproduzem na creche aquilo que vivenciam no cotidiano familiar. A participação da família na realidade dos filhos e o propósito de atender às solicitações dos monitores favorecem o cumprimento de atividades desempenhadas pela instituição e a compreensão dos comportamentos manifestos pelas crianças.

Torna-se necessário entender as características particulares da cultura em que cada criança encontra-se inserida, compreendendo-a como sujeito criativo, indivíduo social, produtora de uma história num processo de construção de conhecimento de si e do mundo. Com isto, existe a necessidade de contato aprofundado com a família, para permitir o 
conhecimento dos valores, dos saberes, das atitudes educativas, possibilitando-se o conhecimento de suas expectativas, medos e necessidades em relação à creche.

É de fundamental importância considerar o vínculo que se estabelece entre o monitor, os pais e a criança. Com empatia e promovendo vínculo de confiança, a adesão da criança e de sua família à creche pode ser facilitada, propiciando uma participação mais ativa e de cooperação dos mesmos no processo de cuidado e de educação.

Deve-se atuar junto à criança, realizando intervenções que promovam melhorias nas ações dos cuidadores frente às necessidades infantis, firmando compromisso com o cuidado à saúde, centrada na atenção integral à criança, no desenvolvimento de ações de prevenção de agravos, de promoção da saúde e de assistência, apontando para a melhoria da qualidade de vida da criança e contribuindo para que ela possa desenvolver todo o seu potencial.

Ressaltamos que os cuidados de saúde às crianças que frequentam creches são de responsabilidade de todos, incluindo pais, monitores, professores e demais funcionários. As instituições de educação infantil devem estar articuladas aos serviços de atendimento à saúde para que a assistência às crianças seja garantida.

Os profissionais de Enfermagem devem conhecer a realidade das creches, das crianças e de seus familiares, discutindo práticas de educação em saúde que viabilizem o aprimoramento das atitudes daqueles envolvidos no cuidado às crianças.

Há a necessidade de um investimento, cada vez maior, por parte dos sistemas públicos na educação infantil para promover práticas educativas e organizacionais que conduzam ao desenvolvimento das crianças e de suas famílias e à consequente melhoria na qualidade do cuidado e da educação.

\section{REFERÊNCIAS}

1 Santos LES. Creche e pré-escola - uma abordagem de saúde. São Paulo: Artes Médicas; 2004. p.244.

2 Longo-Silva G, Toloni MHA, Goulart RMM, Taddei JAAC. Avaliação do consumo alimentar em creches públicas em São Paulo, Brasil. Rev Paul Pediatr. 2012; 3O(1):35-41.

3 Brasil. Constituição da República Federativa do Brasil de 1988. Brasília (DF): Senado; 1988.
4 Brasil. Lei n. 8.069, de 13 de julho de 1990: dispõe sobre o Estatuto da Criança e do Adolescente. Brasília (DF); 1990.

5 Brasil. Lei n. 9.394, de 20 de dezembro de 1996: dispõe sobre as Diretrizes e Bases da Educação Nacional. Brasília (DF); 1996.

6 Scopel RR, Souza VC, Lemos SMA. A influência do ambiente familiar e escolar na aquisição e no desenvolvimento da linguagem: revisão de literatura. Rev CEFAC. 2011;13:0-0.

7 Bogus CM, Nogueira-Martins MCF, Moraes DEB, Taddei JAAC. Cuidados oferecidos pelas creches: percepções de mães e educadoras. Rev Nutr. 2007; 20(5):499-514.

8 Esteves MR, Carrijo GK, Andrade MBT, Santos LES, Ferriani MGC. Influências das relações intrafamiliares no comportamento de crianças de $\mathrm{O}$ a 3 anos que frequentam creches públicas do município de Alfenas-MG na visão dos monitores In: Anais do $17^{\circ}$ SIICUSP; 2009 nov 6-7; São Paulo, Brasil. São Paulo: USP; 2009. 1 p.

9 Heidegger M. Ser e Tempo. Tradução de Márcia de Sá Cavalcante. $4^{\mathrm{a}}$ ed. Petrópolis: Vozes; 1993. p.51.

10 Martins J, Bicudo MAV. A pesquisa qualitativa em psicologia: fundamentos e recursos básicos. $2^{\mathrm{a}} \mathrm{ed}$. São Paulo: Morais; 1994. p.110.

11 Conselho Nacional de Saúde (BR). Resolução n. 196, de 10 de outubro de 1996: diretrizes e normas regulamentadoras de pesquisa envolvendo seres humanos. Brasília (DF); 1996.

12 Esteves CM, Borges ES. O Resgate do vínculo mãe-bebê: estudo de caso de maus tratos. Psicol Cienc Prof. 2007; 27(4):760-75.

13 Lopes RCS, Oliveira DS, Vivian AG, Bohmgahren LMC, Piccinini CA, Tudge J. Sentimentos maternos frente ao desenvolvimento da criança aos 12 meses: convivendo com as novas aquisições infantis. Psicol: Teor e Pesq. 2007; 23(1):05-16.

14. Andrade EM, Nakamura E, Paula CS, Nascimento R, Bordin IA, Martin D. A visão dos profissionais de saúde em relação à violência doméstica contra crianças e adolescentes: um estudo qualitativo. Saude Soc. $2011 ; 20(1): 147-55$.

15 Almeida LS. Mãe, cuidadora e trabalhadora: as múltiplas identidades de mães que trabalham. Rev Dep Psicol, UFF. 2007; 19(2):411-22. 
16 Alves RCP, Veríssimo MDLÓR. Os educadores de creche e o conflito entre cuidar e educar. Rev Bras Crescimento Desenv Hum. 2007; 17(1):13-25.

17 Zaiden MF, Santos BMO, Cano MAT, Nascif Júnior IA. Epidemiologia das parasitoses intestinais em crianças de creches de Rio Verde-GO. Med. 2008; 41(2):182-87.

18 Silva JC, Furtado LFV, Ferro TC, Bezerra KC, Borges EP, Melo ACFL. Parasitismo por Ascaris lumbricoi- des e seus aspectos epidemiológicos em crianças do Estado do Maranhão. Rev Soc Bras Med Trop. 2011; 44(1):100-02.

19 Pastoral da Criança(PR). Guia do líder da Pastoral da Criança. $10^{\mathrm{a}}$ ed. Curitiba. 2007 ; p.304.

20 Silva MRS, Luz GS, Cezar-Vaz MR, Silva PA. Trabalho familiar: distribuição desejada do trabalho doméstico e cuidados dos filhos entre cônjuges. Rev Gaúcha Enferm. Porto Alegre. 2012; 33(1):124-31.

\section{Endereço da autora / Dirección del autor /} Author's address

Michelly Rodrigues Esteves

Avenida dos Bandeirantes, 3900, Campus Universitário, Monte Alegre

14040-902, Ribeirão Preto, SP

E-mail:misscheelly7@yahoo.com.br
Recebido em: 27.07.2011

Aprovado em: 09.07.2012 